\title{
The effects of corruption on Peru's economic growth during the period 1998-2018
}

\author{
Stephany Alessandra Benito Marro ${ }^{\mathrm{a}}$, Leon Rivera Mallma ${ }^{\mathrm{a}}$ and Wagner Vicente-Ramos ${ }^{\mathrm{a}^{*}}$
}

${ }^{a}$ Universidad Continental, Peru

\begin{tabular}{|c|c|}
\hline CHRON I C L E & A B S T RACT \\
\hline $\begin{array}{l}\text { Article history: } \\
\text { Received: February 27, } 2021 \\
\text { Received in revised format: } \\
\text { April } 292021 \\
\text { Accepted: May 11, } 2021 \\
\text { Available online: } \\
\text { May } 11,2021\end{array}$ & $\begin{array}{l}\text { The objective of this research was to determine the effect of corruption on economic growth in Peru } \\
\text { for the period 1998-2018. It was determined how economic growth was affected both in the short } \\
\text { and long term by corruption. The corruption control index was used to measure corruption and the } \\
\text { variation in gross domestic product (GDP) at constant prices was used to measure economic growth. } \\
\text { To determine this effect, the hypothetical deductive method was used as a general method since we } \\
\text { sought to corroborate a hypothesis and as a specific method, we used the Autoregressive Model of }\end{array}$ \\
\hline $\begin{array}{l}\text { Keywords: } \\
\text { Corruption } \\
\text { Economic growth } \\
\text { ARDL } \\
\text { Transmission channels }\end{array}$ & $\begin{array}{l}\text { Distributed Lag (ARDL) since this model adapts well to small samples, likewise we had a non- } \\
\text { experimental research design - longitudinal explanatory. Data were collected from the World Bank } \\
\text { and the Ministry of Education (MINEDU) from } 1998 \text { to } 2018 \text {. As a result of the econometric ARDL } \\
\text { model, it was obtained that corruption had a negative effect on economic growth since an improve- } \\
\text { ment of one percentage point in the corruption index would mean an improvement of } 0.55 \text { percent- } \\
\text { age points in economic growth. Therefore, it is concluded that the effect of corruption has a negative } \\
\text { effect on economic growth as expected according to the reviewed antecedents. }\end{array}$ \\
\hline
\end{tabular}

\section{Introduction}

Corruption is largely due to the loss of values, most of the corrupt do not see this as a moral transgression, they feel shame not for transgressing values but for fear of punishment or the discomfort that would produce to be discovered (Huber, 2016). Likewise, corruption is due to the concentration of power and wealth associated with impunity, corruption is a product that is expected when there are large accumulations of wealth and power and they feel that they are above the law. (Estevez, 2005). This has always existed and will continue to exist as long as human beings are capable of making mistakes and acting with evil and worldwide there is no small degree of corruption that affects rich and poor countries at economic, human, social, political and ethical levels. (Argandoña, 2019). In Latin America corruption as in the world has managed to arouse a high public interest, therefore in the region actions against corruption have been promoted, such as sentences against politicians and businessmen involved in acts of corruption. The Global Corruption Barometer reports that more than 17,000 citizens from 18 countries in the region believe that corruption has increased in their countries, but they also believe that they can contribute to the fight against corruption. (Transparency international, 2019). In Peru the situation is not very different from other Latin American countries, as the country has a high corruption index (35), where zero is used for countries with a high corruption index and 100 for countries that are totally clean. This index places Peru as one of the countries with the highest corruption indexes in the world. (Transparency International, 2019). Robles Laines (2019), in his research work How does corruption affect economic growth in Peru, had as main objective to estimate the effect of corruption on economic growth in Peru in the years 1984-2016. For this he used an autoregressive distributed lags model (ARDL), in which he controlled the effect of growth through variables such as trade openness, capital accumulation, the public sector and education. The author expected the effects of corruption on economic growth to be negative in the long run based on all the literature reviewed and * Corresponding author.

E-mail address: wvicente@ continental.edu.pe (W. Vicente-Ramos)

(C) 2021 by the authors; licensee Growing Science, Canada doi: 10.5267/j.ac.2021.5.006 
was able to contrast this with his results, where a one percentage point improvement in the corruption index resulted in a 0.083 percentage point improvement in GDP per capita in the long run. This would indicate that corruption is indeed considered a problem for economic growth.

Therefore, the main objective of this research is to estimate the effect of corruption on economic growth in both the short and long term for Peru during the years 1998-2018.

\section{Literature review}

\subsection{Corruption}

Corruption is defined as "acts committed at a high level of government that distort policies or the central functioning of the state, allowing leaders to benefit at the expense of the public good." (Transparency International, 2020). This concept can be applied in both the public and private sectors. In the private sector, some nations have as a basis for economic growth the fair and just competition between companies, so there should be a good control of corruption. In the public sector corruption is the one that aggravates the responsibility of public and business agents since they are the ones who should protect human rights and they are the ones who end up violating them more, in other words, the resources that should be destined to vulnerable sectors to protect the neediest are directed to those who have the most (Piovesan et al., 2018). Corruption, bad governance, and lack of competitiveness are the answer to why some countries remain developed and why others remain stuck in underdevelopment. Corruption has two immediate effects, the first is that it generates high costs that discourage investment within the country and the second effect estimates capital flight. It is also stated that there is a global consensus that corruption in government and business slows economic growth and can perpetuate poverty (Alcaide Zugaza, 2004, 2015).

In addition, corruption for the economy is the result of an institutional arrangement used to solve problems of resource allocation, public and private resources and skills are used for the own purposes of some. This issue began to be studied in economics since the 80 's, however, that does not mean that before that corruption did not exist, in fact some historians say that it was born simultaneously with the state. This problem can be solved with economic contributions that help to understand the rationality and dynamics of corruption, but these solutions will not be very different from the contributions that other social sciences can provide. (Gómez).

\subsubsection{Economic rationality of corruption}

According to Estévez (2005) "There are five structural factors that shape corruption: a) Concentration of power and wealth associated with impunity, b) Deepening of social inequalities both materially and in terms of rights and duties, c) Instrumental rationality-efficiency-pragmatism, d) Fall of certain values as a basis for public decisions technocracy, and e) Selfishnessindividualism-individual reason".

Based on the structural factor mentioned in the previous paragraph, selfishness-individualism, Mendoza (2000) stated that the corrupt person is a maximizing agent, who manages to reach an optimal level of corruption according to his preferences and objectives, where the sum of his licit plus illicit income is his budget constraint. The net income is the difference between the benefits obtained by corruption and the cost of executing this action; this cost is the sum of the opportunity cost, the moral cost and the cost of execution. Therefore, the author concludes that corruption is the reflection of individuals seeking to maximize their utility. Knowing that the net income of the corrupt is the income from the corrupt act minus the total cost, the corrupt will be larger if his income from corruption is increasingly higher and the costs are lower. This means that the larger the economic size of the institutions, the greater the power of the corrupt and the lower the penalty, moral and enforcement costs, the greater the net income of the corrupt and this will continue to encourage him to continue committing acts of corruption.

\subsection{Economic growth}

Musa et al. (2016), aimed to find the relationship between corruption and economic growth in six West African countries (Nigeria, Ghana, Cameroon, Ivory Coast, Chad, and Togo) using an econometric model. In this research work, corruption perception index, foreign direct investment and trade openness were considered as independent variables. The last two variables, foreign direct investment and trade openness are indirect transmission channels of corruption to economic growth. They concluded that corruption has a strong negative effect on economic growth, if the corruption perception index decreases by one percentage point, economic growth would increase by 0.1433 percentage points in these countries. Bigio et al. (2017) conducted a similar study. They reported the relationship between corruption and several indicators of economic development with empirical evidence collected from several Latin American countries. They show that corruption negatively affects variables that are associated with economic development: economic stability, quality of public spending on education and health, tax revenues, inequality, poverty, investment, and economic growth. For this, they estimated a dynamic panel data model that had a sample of 104 countries during the period 1980-205, the relevant results for this research were that by improving the 
corruption indexes of Latin American countries the growth of GDP per capita increased by $0.8 \%$ and by doing the same for Peru the growth of GDP per capita increased by $0.6 \%$.

It is necessary to know the transmission channels through which corruption affects economic growth.

For this reason, Pellegrini and Gerlagh (2004), in their article on the effects of corruption on economic growth and transmission channels, were able to demonstrate the direct and indirect channels through which corruption affects economic growth. The authors focused on the indirect transmission channels, income, trade policy, education, and political stability. These variables went through a regression analysis to estimate the effects of corruption on economic growth. The results showed that an increase in the standard deviation of the corruption index would cause investment to decrease by 2.46 percentage points and in turn economic growth would decrease by 0.34 percent per year. Likewise, another transmission channel that would cause growth to decrease by 0.30 percent per year is trade openness, which would decrease by 0.19 if the corruption index increases. The effect of corruption on economic growth is 81 percent explained by these channels.

In addition, Mo (2000) conducted research similar to that mentioned in the previous paragraph and aimed to introduce a new perspective on the role of corruption on economic growth and the estimation of growth transmission channels. Mo used the ordinary least squares (OLS) method. Through this he was able to demonstrate that a $1 \%$ increase in the level of corruption reduces growth by $0.72 \%$ and also determined that the most important transmission channel through which corruption affects growth is political instability which represents $53 \%$ of the total effect, he also stated that corruption reduces the level of human capital and the search for private investment, it should be noted that Mo in this research considered investment, human capital and political stability as transmission channels.

On the other hand, Wey, (2001) states that some people in Asia may think that they have gained acceleration through corruption, with some bribe or something. However, it is shown that the overall effect of corruption on economic growth has a negative effect not only in Asia but worldwide. They also point out that according to research by other authors, a corrupt country grows slowly compared to a non-corrupt one. The channels through which corruption hinders economic development are the reduction of domestic investment, reduction of foreign investment, disproportionate increase in government spending, but not in education, health, and infrastructure maintenance, but in projects with higher costs, but with less efficiency.

Corruption can only be fought in the long term and it is important to know what the transmission channels are and to understand how they work in order to limit the negative effects of corruption on economic growth.

After analyzing how corruption negatively affects economic growth, it is important to always keep in mind that the most serious consequence of corruption in a country is not economic, but the most serious consequence is the costs it generates on democracy, equality, and social capital (Isaza Espinosa, 2009).

\section{Variables and hypotheses}

To determine the econometric model, independent variables were used as control variables for economic growth. Initially, variables such as trade openness and political stability were considered, but they had cointegration problems and were not very significant for the model, which distorted the results, so it was decided to remove these variables. This cointegration could be due to the fact that these variables act as transmission channels from corruption to economic growth, as mentioned by Mo (2000). Likewise, the labor represented by the labor force participation rate was also considered, but it also had to be removed because it was a non-significant variable, which could be due to the chosen indicator. After all these modifications, the model only has the following as independent variables:

a) Corrup $=$ corruption perception index

b) $\quad \mathrm{Fbk}=$ gross capital strength

c) matric $=$ enrolled at the primary level

There is only one dependent variable, which is economic growth, represented by the change in GDP at constant prices.

a) GDP $=$ change in GDP at constant prices

Based on these variables, the following hypotheses are established

HG: A high corruption rate has a negative effect on economic growth, over the period 1998-2018.

HE1: The effect of corruption on economic growth in the short term is negative, over the period 19982018.

HE2: The long-term effect of corruption on economic growth is negative, over the period 1998-2018. 


\section{Methodology}

The general research method is hypothetico-deductive or falsifications, which follows these steps: we start from a problem, we look for theories through which we seek to solve the problem, we eliminate the errors to which the theories are exposed and finally we designate a new problem that emerges when the errors are contrasted with the tentative theories. This procedure consists of starting from a basic hypothesis and deducing what the consequences will be with the help of formal theories (Mendoza Bellido, 2014). The present work was carried out in this way, I pose a basic hypothesis based on formal theories of economic growth and corruption; therefore, the method is hypothetical deductive. On the other hand, the research design is non-experimental since no variable was altered and due to its temporal scope, it is longitudinal because the changes produced over time in the same sample were analyzed.

The present research, as mentioned, is longitudinal, so time series of corruption control and economic growth indexes collected from the World Bank from 1998 to 2018 were used. The data was collected in 1998 since the World Bank issued the accurate data for corruption control. The time series of Peru's growth and corruption rates are the population. The sample is the time series of the change in GDP at constant prices and the time series of the corruption indexes of Peru during the period 1998-2018, which are in total 20 data.

The specific research method will be the ARDL econometric model (autoregressive method of distributed lags). This method was chosen because according to Robles Laines (2019), the authors Adom, Bekoe and Akoena (2012) state that in this method it is not necessary that all variables have the same order of integration, that is, it can work for a combination of variables I (0) I (1), they also state that this method is more efficient in the case of small samples.

\section{Results}

\subsection{Description of field work}

In this research work we used annual time series of GDP at constant prices with base year 2010, time series of the corruption control index and used variables such as gross capital formation, labor force and education in order to have a control of economic growth. All previously collected series were obtained from the World Bank and MINEDU. Excel was used to sort the data and estimate the variation of GDP at constant prices, and then export all the data to Stata in order to estimate the ARDL model. Table 1 shows the main descriptive statistics of the variables mentioned in the previous paragraph.

Table 1

Descriptive statistics

\begin{tabular}{lccccc}
\hline & OBS & MEAN & STD. DEV & MIN & MAX \\
\hline Lpbi & 21 & 25.58443 & .3242003 & 25.13384 & 26.0533 \\
Lcorrup & 21 & 3.797164 & .1424821 & 3.526361 & 4.043051 \\
Lfbk & 21 & 23.93502 & .5373991 & 23.22911 & 24.56766 \\
Lflab & 21 & .0185536 & .0185536 & 4.373954 & 4.45959 \\
Matric & 21 & .0866548 & .0866548 & .59 & .89 \\
\hline
\end{tabular}

Table 1 shows the main descriptive statistics of the selected data. All the data obtained were collected from the World Bank and MINEDU, all these data for the period 1998-2018, are few data (20), and for this reason the statistical methods might not be accurate. The correlation matrix of the variables used in the econometric model is shown below.

Table 2

Correlation matrix

\begin{tabular}{ccccc}
\hline & LPBI & LCORRUP & LFBK & LFLAB \\
\hline LPBI & 1.0000 & & & \\
LCORRUP & -0.4429 & 1.0000 & 1.0000 & \\
LFBK & 0.9638 & -0.3919 & 0.5341 & 1.0000 \\
LFLAB & 0.3984 & -0.1090 & 0.9069 & 0.4161 \\
\hline
\end{tabular}

Table 2 shows the correlation matrix, which, being a time series, could show spurious relationships. However, we clearly visualize a non-strong inverse relationship between lpbi (real GDP) and lcorrup (corruption index), a strong relationship between real GDP and both lfblk (Gross Capital Formation) and matric (RBS enrollment rate). Interestingly, there is also a strong positive linear association between $l f b k$ and matric. On the other hand, analyzing the channels of transmission of corruption, it can be observed that, if there is a one percentage point increase in gross capital formation, growth would improve by 0.96 percentage points. If there is a one percentage point increase in the labor force, growth would improve by 0.39 percentage points. And if education were to increase by one percentage point, economic growth would increase by 0.96 percentage points. 


\subsection{Model specification}

In this research work, the dependent variable is economic growth, and the independent variable is corruption. For this reason, the following linear mathematical function describes well the relationship between both variables.

$$
y_{t}=\left(\boldsymbol{x}_{t}\right)
$$

where the dependent variable $\boldsymbol{Y}$ is a vector of economic growth measured from the logarithm of real GDP (lpbi) and $\boldsymbol{X}$ is a matrix of independent variables: the smoothed corruption index (lcorrup), the smoothed Gross Capital Formation-FBK (lfbk), the smoothed labor force (lflab) and the RBE enrollment rate (matric). From Eq. (1), the economic model can be explicitly stated as a linear equation of the form:

$$
l p b i_{t}=\beta_{0}+\beta_{1} l_{\text {corrup }}+\beta_{2} l f b k_{t}+\beta_{3} \text { lflab } f_{t}+\beta_{4} \text { matrict },
$$

where the subscript $t=1998, \ldots, 2018$

Due to the micronumerosity problem (small sample), the OLS estimation would have inconsistencies, so it was decided to use the ARDL (autoregressive distributed lag) model, whose virtue is precisely that it usually works with small samples. Also, as Adom, Bekoe and Akoena (2012) point out, in this model it is not necessary for all the variables to have the same order of integration. As an additional requirement, it is restricted to the fact that the variables (whether dependent or independent) must become stationary when applying at most first differences; that is, they must be either I (0) or I(1).

In general, an ARDL_((r,s)) model is stated as:

$$
Y_{t}=\alpha_{0}+\mu_{0 t}+\sum_{i=0}^{r} \theta_{i} \Delta Y_{t-i}+\sum_{i=0}^{s} \varphi_{i} \Delta X_{t-i}+\alpha_{1} Y_{t-1}+\alpha_{2} X_{t-1}+\alpha_{3} Z_{t}+\varepsilon_{t}
$$

where $\alpha_{0}$ is the intercept; $\mu_{0}$ is the coefficient of the trend; $\theta_{i}$ y $\varphi_{j}$ are the short-run coefficients; and $\alpha_{1} y \alpha_{2}$ are the longterm relationships; $Y_{t}$ is the dependent variable and $\Delta Y_{t-i}$ are the differences of its $i$-th lag; $\boldsymbol{X}_{t-1}$ is a vector of lagged independent variables, and $\Delta \boldsymbol{X}_{t-j}$ are their lagged differences; $\boldsymbol{Z}_{t}$ is a vector of exogenous variables and $\varepsilon_{t}$ is the white noise error that under one assumption is uncorrelated.

\subsection{Data and application of the econometric model}

Based on the papers by Pellegrini \& Gerlagh, (2004), Mo, (2000), and (Wey, 2001) to determine the independent variables that would accompany corruption, the form of the function that was estimated is shown in the following line.

$$
Y_{t}=f\left(\text { corrup }_{t}, f b k_{t}, \text { flab }_{t}, \text { matric }_{t}\right)
$$

From the above function, $Y_{t}$ is the change in GDP at constant prices, corrup is the corruption control index, $f b k$ is gross capital formation, flab is the labor force, and matric is primary school enrollment. The data were obtained from development and governance indicators of the World Bank and MINEDU. Next, in order to achieve efficient results, all the variables were loglinearized except for matric because it would lose significance. By applying these changes, the econometric model can be presented as follows:

$$
l p b i_{t}=\alpha_{0}+\mu_{0 t}+\sum_{i=0}^{r} \theta_{i} \Delta l p b i_{t-i}+\sum_{i=0}^{s} \varphi_{i} \Delta \text { lcorrup }_{t-i}+\alpha_{1} l p b u_{t-1}+\alpha_{2} \text { lcorrup }_{t-1}+\sum_{i=0}^{s} \varphi_{i}^{\prime} \Delta X_{t-i}^{\prime}+\alpha_{3} X_{t-1}^{\prime}+\varepsilon_{t}
$$

where $\boldsymbol{X}_{t-1}^{\prime}$ comprises, all other lagged independent variables influencing $l p b i_{t}$ y $\Delta \boldsymbol{X}_{t-j}^{\prime}$ their lagged differences $j$ times.

\subsection{Unit root tests}

It is necessary to perform the unit root tests, to check that none of the variables is an $\mathrm{I}(2)$ process, since as mentioned above ARDL works with I(0), I(1) series, or it can be with a combination of both but it does not work with I(2).For the present work the Augmented Dickey Fuller unit root test was used for each variable. After performing the unit root test on each variable, it could be seen that all variables are clearly nonstationary in levels but become stationary when the first difference is taken. By making sure that our variables have process I (0) and I (1), the ARDL model can be run. A summary of the above paragraph can be seen in Table 3 below.

\subsection{Econometric model results}

After analyzing that the variables comply with the conditions, the optimal number of lags had to be determined using the varsoc command, the result of which (see Table 4) indicates that the model deserves to be lagged one period. The table shows six different statistics that allow us to recommend the optimal number of lags for the model. 
Although it is true that the number of lags is guided by the estimation, it is important to point out that as the model progresses, in some cases the number of lags will be chosen according to how the ARDL model behaves and not because of the strict recommendation offered by default by the estimation.

Table 3

Optimal lags for lpbi

Selection-order criteria

Sample: 2002-2018

\begin{tabular}{|c|c|c|c|c|c|c|c|c|}
\hline lag & LL & LR & $\mathrm{df}$ & $\mathrm{p}$ & FPE & AIC & HQIC & SBIC \\
\hline 0 & 4.07639 & & & & .04591 & -.244281 & -.234537 & -.146256 \\
\hline 1 & 45.1158 & $82.079 *$ & 1 & 0.000 & $.000414 *$ & $-4.9548 *$ & $-4.94019 *$ & $-4.80777^{*}$ \\
\hline 2 & 45.2785 & .32539 & 1 & 0.568 & .00046 & -4.8563 & -4.83681 & -4.66025 \\
\hline 3 & 46.3836 & 2.2102 & 1 & 0.137 & .000458 & -4.86866 & -4.8443 & -4.6236 \\
\hline 4 & 46.4065 & .04576 & 1 & 0.831 & .000521 & -4.75371 & -4.72448 & -4.45963 \\
\hline
\end{tabular}

Endogenous: lpbi

Exogenous: lcorrup_cons

Next, we test whether the variable has a structural lpbi has a structural break that could distort the ARDL model. As can be seen, the null hypothesis of structural stability is not rejected. Model 4 can now be estimated according to the variables referenced above. Table 4 shows the regression of the ARDL model.

Table 4

ARDL model with lags $(1,2,4,4)$

Sample: $2002-2018$

Log likelihood $=95.677555$

\begin{tabular}{|c|c|c|c|c|c|c|}
\hline D.lpbi & Coef. & Std. Err. & $\mathrm{t}$ & $P>|t|$ & \multicolumn{2}{|c|}{ [95\% Conf. Interval ] } \\
\hline ADJ & & & & & & \\
\hline \multicolumn{7}{|l|}{ lpbi } \\
\hline L1. & 1.015622 & .1714409 & 5.92 & 0.027 & .2779718 & 1.753273 \\
\hline \multicolumn{7}{|l|}{ LR } \\
\hline lcorrup & -.5572668 & .0241317 & -23.09 & 0.002 & -.6610972 & -.4534364 \\
\hline lfbk & -.137764 & .0134836 & -10.22 & 0.009 & -.1957791 & -.0797489 \\
\hline matric & 4.713054 & .0894565 & 52.69 & 0.000 & 4.328154 & 5.097954 \\
\hline \multicolumn{7}{|l|}{ lcorrup } \\
\hline D1. & -.5075977 & .081094 & -6.26 & 0.025 & -.8565171 & -.1586784 \\
\hline LD. & -.3193255 & .04659 & -6.85 & 0.021 & -.519786 & -.1188651 \\
\hline \multicolumn{7}{|l|}{ lfbk } \\
\hline D1. & .0129994 & .0222811 & 0.58 & 0.619 & -.0828684 & .1088672 \\
\hline LD. & -.2635392 & .0462622 & -5.70 & 0.029 & -.4625892 & -.0644891 \\
\hline L2D. & -.3029864 & .0493697 & -6.14 & 0.026 & -.5154071 & -.0905658 \\
\hline L3D. & -.1519406 & .0209192 & -7.26 & 0.018 & -.2419488 & -.0619325 \\
\hline \multicolumn{7}{|l|}{ matric } \\
\hline D1. & 4.387573 & .6881352 & 6.38 & 0.024 & 1.426766 & 7.34838 \\
\hline LD. & 3.247767 & .5461356 & 5.95 & 0.027 & .8979349 & 5.597599 \\
\hline L2D. & 2.729348 & .4248065 & 6.42 & 0.023 & .9015528 & 4.557143 \\
\hline L3D. & 1.442209 & .2072141 & 6.96 & 0.020 & .5506386 & 2.333779 \\
\hline cons & -27.99673 & 4.662368 & -6.06 & 0.026 & -47.89082 & -8.102636 \\
\hline
\end{tabular}

After having run several models with all the variables and with different numbers of lags, it was determined thanks to the Akaike information and the Bayesian information criterion that the best econometric model is the one shown in Table 5.

The LR section comprises the long-run (log-run) effects, the short-run effects are in the SR (short-run) section and the ADJ (speed-of-adjustment coefficient) section measures how strongly the dependent variable reacts to a deviation from the equilibrium relationship in one period or, in other words, how fast an equilibrium distortion is corrected. 
Regarding the long-term relationships, it is worth mentioning that all relationships are statistically and economically significant. With respect to corruption, a one percentage point improvement in corruption would result in a 0.56 percentage point improvement in economic growth. The fact that the independent variable, gross capital formation, is so significant is explained by the fact that it is a transmission mechanism of corruption to economic growth as mentioned by several authors in the literature review.

In the short term, the result is that an improvement in corruption would improve economic growth by 0.51 percentage points.

The results in both the short and long term corroborate the hypotheses proposed and coincide with the literature reviewed.

The ARDL model presented in Table 5 is the best among several other ARDL models. This was determined after analyzing the Akaike scores and Bayesian information criteria of all the models run.

From Table 5 and Equation 4, as suggested by Pesaran, Shin \& Smith (2001), the following conjectures should be tested with the F-statistic:

$$
\begin{aligned}
& H_{0}: \alpha=0 \cap\left(\sum_{j=0}^{s} \varphi_{j}=\mathbf{0}\right) \\
& H_{0}: \alpha \neq 0 \cup\left(\sum_{j=0}^{s} \varphi_{j} \neq \mathbf{0}\right)
\end{aligned}
$$

If the null hypothesis is rejected, the t-statistic should be used, but if $\mathrm{H}_{-} 0$ is not rejected, the conventional Z-test (Wald test) should be used to evaluate the individual significance of the coefficients. In this case, due to the number of observations, the F statistic proposed by the authors cannot be used, but the $t$ statistic can be used.

To evaluate the statistical significance of each variable in a model (such as the one in Table 4), statistical theory proposes the Student's t-test statistic:

$$
t=\frac{\hat{\beta}_{j}-\beta_{j}}{e e\left(\hat{\beta}_{j}\right)}=\frac{\hat{\beta}_{j}}{e e\left(\hat{\beta}_{j}\right)}, \quad j=1, \ldots, 8
$$

where ee (.) is the standard error of the coefficient and under the null hypothesis $\beta_{j}=0$. Each of the test statistics is shown in Table 4. $t$ is shown in Table 4. All that remains is to see whether these statistics fall in the rejection or non-rejection region of the distribution. $t$.

Then, from the values of " $t$ " (test statistics) in Table 4, it can be concluded that all variables are significant except. $D 1$. lf $b k$. It should be noted that the trend component had been added to the model in Table 4, but it is not significant and even causes the model to explode, which is why it was removed. Removing the trend would not affect the model, since there may or may not be a trend in the equations of an econometric model (Pesaran, Shin, \& Smith, 2001).

Table 5 below shows the correlation at 4 lags. As can be seen, according to the p-value, the null hypothesis is not rejected, concluding that the model has no first order autocorrelation (the other orders are not defined, so it does not exist there either). The same conclusion is reached with the Durbin test.

\section{Table 5}

Autocorrelation test to the ARDL model $(1,2,4,4)$

Breusch-Godfrey LM test for autocorrelation

\begin{tabular}{crcc}
\hline Lags $(\mathrm{p})$ & $\mathrm{df}$ & Prob $>$ F \\
\hline 1 & 12.542 & $(1,1)$ & 0.1752 \\
2 & 8.500 & $(2,0)$ &. \\
3 & 5.667 & $(3,0)$ &. \\
4 & 4.250 & $(4,0)$ &. \\
\hline
\end{tabular}

$\mathrm{H}_{0}$ : no serial correlation

Table 6 below shows that according to the p-values, the homoscedasticity hypothesis is not rejected for the model in Table 4. 
Table 6

Heteroscedasticity test to the ARDL model $(1,2,4,4)$

White's test for H0: homoskedasticity against Ha: unrestricted heteroskedasticity

Chi2 (16) $=17.00$

Prob $>$ chi $2=0.3856$

\begin{tabular}{cccc}
\hline & Cameron \& Trivedi’s decomposition of IM-test & \\
\hline Source & Chi2 & df & P \\
\hline Heteroskedasticity & 17.00 & 16 & 0.3856 \\
Skewness & 11.02 & 14 & 0.6847 \\
Kurtosis & 2.38 & 1 & 0.1227 \\
\hline Total & 30.40 & 31 & 0.4967
\end{tabular}

Table 7, on the other hand, allows us to evaluate normality. As can be seen, the null hypothesis of normality is not rejected.

Table 7

Normality test to ARDL $(1,2,4,4)$ model

Skewness and kurtosis tests for normality

\begin{tabular}{cccccc}
\hline & & & & \multicolumn{3}{c}{-------Join test------- } \\
Variable & Obs & Pr (skewness) & Pr (kurtosis) & Adj chi2 (2) & Prob >chi2 \\
\hline residuals & 17 & 0.9564 & 0.4895 & 0.50 & 0.7786 \\
\hline
\end{tabular}

Finally, Table 8 shows the structural break test. With the p-value, it is clearly concluded that the model under analysis does not show a break.

Table 8

Break test to ARDL $(1,2,4,4)$ model

Cumulative sum test for parameter stability

Sample: $2002-2018$

Number of obs $=17$

H0: No structural break

\begin{tabular}{ccccc}
\hline Statistic & Test Statistic & $1 \%$ Critical Value & $5 \%$ Critical Value & $10 \%$ Critical Value \\
\hline recursive & 0.5740 & 1.1430 & 0.9479 & 0.850 \\
\hline
\end{tabular}

\section{Contrasting results}

After estimating the ARDL model to determine the effect of corruption on economic growth, we will check whether the hypotheses made in part 3 were correct.

General Hypothesis: A high corruption index has a negative effect on economic growth in the period 19982018. According to the results found, the variable lcorrup has a negative influence on the lpbi, thus validating the hypothesis.

- Specific Hypothesis 1: The effect of corruption on economic growth in the short term is negative, in the period 19982018. According to the results found, the short-term variables negatively influence the lpbi. $\Delta l c o r r u p_{t-j}$ negatively influence the lpbi, thus validating the hypothesis.

- Specific Hypothesis 2: The effect of corruption on economic growth in the long run is negative, in the period 19982018. According to the results found, the long-run variable lcorrup $_{t}$ has a negative influence on the lpbi, thus validating the hypothesis.

In summary, the general hypothesis was highly contrasted because with the ARDL model shown in the previous section it could be seen that corruption does have a negative effect on Peru's economic growth in the period 1998-2018. With respect to specific hypothesis 1 , the effect of corruption is negative in the short term. In specific hypothesis 2 , the effect of corruption on growth is also negative in the long term.

\section{Discussion of results and conclusions}

The results obtained in the ARDL econometric model coincide with all the precedents reviewed that affirmed that corruption has a negative effect on economic growth. 
In the short term, it was shown that if the corruption index improves by one percentage point, growth would improve by 0.51 points. Likewise, we see that in the long term if the corruption perception index improves by one percentage point, growth would improve by 0.56 percentage points. We also see that the variable that has a direct impact on the GDP growth rate at constant prices is gross capital formation, which could be because they are acting as a transmission channel as mentioned by Pellegrini and Gerlagh (2004) and Wey (2001).

In addition, Table 6 shows that in the long term if the corruption control index improves by one percentage point, economic growth would improve by 0.56 percentage points, this result has similarity with what was mentioned by (Robles Laines, 2019), who said that in the long term an improvement of one percentage point in corruption would mean an improvement of 0.083 percentage points in GDP. Likewise, the long-term result obtained in the present work has similarity with the results of the work of (Bigio \& Ramirez, 2006) who stated that in the long run a one percentage point improvement in corruption would generate a GDP per capita growth of $0.6 \%$.

On the other hand, a limitation was that in order for the ARDL model to be stable, a variable with low significance, the labor force, had to be removed, which could be due to the chosen indicator.

\section{References}

Adom, P. K., Bekoe, W., \& Akoena, S. K. K. (2012). Modelling aggregate domestic electricity demand in Ghana: An autoregressive distributed lag bounds cointegration approach. Energy policy, 42, 530-537.

Alcaide Zugaza, L. (2004). Corruption: obstacle to growth and competitiveness. University of Saussex.

Alcaide Zugaza, L. (2015) Is corruption an obstacle to development and economic growth? A micro, macro and empirical analysis- Case studies: Haiti and Morocco. Madrid : University of San Pablo.

Argandoña, A. (2019). La corrupción . IESE.

Bigio, S., \& Ramirez Rondán, N. (2017). Corruption and development indicators in Peru and the world: an empirical review.

Estévez, A. (January 2005). Theoretical reflections on corruption: its political, economic and social dimensions. Scielo, 4386. http://ve.scielo.org/scielo.php?script=sci arttext\&pid=S1315-99842005000100004

Gómez, C. M. (n.d.). The economic analysis of corruption. Alcalá de Henares: Universidad deAlcalá.

Huber, L. (2016). Corruption and transparency. Consosrcio de investigación económica y social (CIES).

INEI. (2017). Panorama de la Economía Peruana 1950-2016. Lima.

Isaza Espinosa, C. (2009). Dialogue with economic theories of corruption. Universidad Externado de Colombia. Bogotá: Fundación Método. https://papers.ssrn.com/sol3/papers.cfm?abstract_id=1393670

Mendoza Bellido, W. (2014). The methodology of economic research. In W. Mendoza Bellido, Cómo investigan los economistas: Guía para elaborar y desarrollar un proyecto de investigación (pp. 2170). Lima: Fondo editorial de la Pontificia Universidad Católica del Perú.

Mendoza, J. L. (2000). Análisis económico de la corrupción. Universidad Nacional Mayor de San Marcos. Retrieved from http://200.62.146.19/bibvirtualdata/publicaciones/economia/18/a07.pdf

Mo, P. H. (2001). Corruption and economic growth. Journal of comparative economics, 29(1), 66-79. doi:10.1006/jcec.2000.1703.

Musa, A., Rano, A., \& Mansur, I. (2016). Impact of corruption on Economic Growth. Journlal of Educational Policy and Entrepreunerial Research (JEPER), 3(07), 188-201. Retrieved from www.ztjournals.com

Pellegrini, L., \& Gerlagh, R. (2004). Corruption's effect on growth and its transmission channels. Kyklos, 57(3), 429-456.

Pesaran, M. H., Shin, Y., \& Smith, R. J. (2001). Bounds testing approaches to the analysis of level relationships. Journal of Applied Econometrics, 16(3), 289-326. doi:10.1002/jae.616.

Piovesan, F., Dias Rodrigues, A., Alonso Olmos, E., Fernandes de Lima Lira, L., \& Mesquita Nunes, T. (2018). La corrupción y los derechos humanos en Brasil. En C. Tablante y M. Morales Antoniazzi (eds.), Impacto de la corrupción en los derechos humanos (pp. 83-140). Querétaro: Instituto de Estudios Constitucionales del Estado de Querétaro.

Robles Laines, J. A. (2019). how does corruption affect economic growth in Peru? (Undergraduate thesis).

Universidad de Lima, Lima, Peru. from http://repositorio.ulima.edu.pe/bitstream/handle/ulima/8373/Robles_Laines_corrupcion_Peru.pdf?sequence=1\&isAllowed $=\mathrm{y}$

Transparency international. (September 23, 2019). Retrieved from Transparency international: https://www.transparency.org/news/feature/que_piensan_las_personas_corrupcion_en_america_la tina_y_el_caribe

Transparency International. (2019). Corruption Perceptions Index $20 \overline{19}$. Retrieved from https://www.transparency.org/cpi2019?/news/feature/cpi-2019

Transparency International. (2020). Transparency International. Retrieved from Transparency International: https://www.transparency.org/whoweare/organisation/faqs_on_corruption

Wey, S.-J. (2001). Corruption in Economic Development: Beneficial Grease, minor Annoyance, or Major Obstacle? Harvard University and National Bureau of Economic Research. 
(C) 2021 by the authors; licensee Growing Science, Canada. This is an open access article distributed under the terms and conditions of the Creative Commons Attribution (CC-BY) license (http://creativecommons.org/licenses/by/4.0/). 